\title{
Transanal endoscopic microsurgery: exploring its indications and novel applications. A narrative review
}

\author{
Xiaoqiang Xue ${ }^{1}$, Guole Lin $^{2}$ \\ ${ }^{1}$ Department of Urology, Peking Union Medical College Hospital, Chinese Academy of Medical Sciences and Peking Union Medical \\ College, Beijing, China \\ 2Department of General Surgery, Peking Union Medical College Hospital, Chinese Academy of Medical Sciences and Peking Union \\ Medical College, Beijing, China
}

Videosurgery Miniinv 2022; 17 (1): 95-103

DOI: https://doi.org/10.5114/wiitm.2021.108811

\begin{abstract}
Featuring some advantages of endoscopy and microsurgery, transanal endoscopic microsurgery (TEM) was first introduced in treating local early-stage rectal lesions in 1983. However, its applications to rectal surgery have remained virtually unchanged over the past 38 years. This review aims to describe some well-accepted indications for TEM and showcase other novel but successful applications. In this review, we conducted a thorough English literature review on the applications of transanal endoscopic microsurgery in the PubMed database. Published original articles, case reports, and letters from 1983 to 2020 were included. Retrieved articles were discussed and conclusions were made. The results showed that applications of TEM could be more flexible and extended, namely, TEM's niche applications in advanced rectal cancer after neoadjuvant chemoradiotherapy, neuroendocrine tumor, gastrointestinal stromal tumor, fistula, solitary rectal ulcer syndrome, benign stricture, and transanal total mesorectal excision are promising, while prospective studies are needed.
\end{abstract}

Key words: transanal endoscopic microsurgery, rectal carcinoma, neuroendocrine tumor, gastrointestinal stromal tumor, indication.

\section{Introduction}

Transanal endoscopic microsurgery (TEM) was first introduced by Buess et al. in 1983 as a technique that combined features of endoscopy and microsurgery to acquire full-thickness excisions with disease-free margins [1, 2]. With the help of its magnified vision by stereoscopes and inflated endoluminal space by carbon dioxide insufflation, not only could surgeons have a clearer view of the neoplasm, but they could easily reach lesions in the middle to upper rectum without laparotomy. Moreover, owing to its milder surgical impacts, TEM was reported to be a palliative procedure for advanced tumors, too [3]. Other advan- tages such as earlier discharge, fewer perioperative complications, and satisfactory regional recurrence have been reported as well [4].

Although widely used, the major applications of TEM have remained barely unexpanded for the past three decades. Its novel applications are yet to be explored. This might partially be because clinicians were comparatively conservative about its theoretically general applicability.

\section{Aim}

To present some well-accepted indications for TEM and showcase its other novel but practical applications.

\section{Address for correspondence}

Prof. Guole Lin, Department of General Surgery, Peking Union Medical College Hospital, Chinese Academy of Medical Sciences and Peking Union Medical College, Beijing, China, e-mail: general3858@sina.com 


\section{Material and methods}

A comprehensive literature search was conducted in the PubMed database for all relevant English papers published between 1983 and 2020. When a new result was regarded as relevant, a thorough search would be performed both in acronyms and full names. Keywords we initially used were "rectal carcinoma", "transanal endoscopic microsurgery", "application”, "indication”. Even if recent articles were prioritized, earlier works with meaningful results and relevant new applications were referenced if necessary. Extended research keywords were: "gastrointestinal stromal tumor", "neuroendocrine tumor", "solitary rectal ulcer syndrome", "benign stricture", "transanal total mesorectal excision", "neoadjuvant therapy" and "fistula". Note that the technique of TEM we discuss here refers specifically to the surgical system produced by Richard Wolf GmbH (generally known as the Wolf corporation). Published articles on similar equipment, for instance, using transanal endoscopic operation devices, were excluded.

Studies published as case reports and letters were also considered valid. Oral reports from meetings and seminars were excluded. After distinguishing germane titles, apropos abstracts were reviewed, and full-text papers were identified for their eligibility. Retrieved articles were independently extracted then discussions were made.

\section{Traditional indications}

\section{Benign adenomas}

The original indications of TEM were well defined by Buess et al. as sessile rectal adenomas and pT1 staging low-risk carcinomas [1, 2]. For benign adenomas, a full-thickness excision was considered as a standard procedure and because of this, TEM tended to acquire a lower local recurrence rate than other piecemeal dissection procedures [2].

Large sample series had shown promising postoperative outcomes of TEM in treating rectal adenomas; the local recurrence rate was reported to be less than $5 \%$, when local recurrence was detected, supplementary second time TEM (re-TEM) was feasible and its results were satisfactory [5, 6]. Platell found in a prospective study that the 5-year cumulative incidence for local recurrence in 128 cases was $3.1 \%$ after a median follow-up of 4.2 years [7]. This is so far the only recorded pro- spective study regarding the treatment of rectal adenoma by TEM.

Some researchers investigated further to explore connections between TEM and its regional recurrence rate in benign adenomas. Allaix et al. investigated 293 cases and reported that a positive margin was verified to be an independent risk factor for local recurrence [8], which was in line with previous studies by Whitehouse et al. $[9,10]$. Note that tumor size was not a contraindication against TEM. A retrospective study by Arezzo et al. suggested that large circumferential adenomas ( $7 \mathrm{~cm}$ in median longitudinal extent) were also resectable via TEM while no significant difference in local recurrence was found [11].

When comparing TEM with other techniques in treating benign adenomas, TEM was preferable in one aspect or another. A retrospective study involving 292 patients showed that TEM had a lower early recurrence rate than that in endoscopic mucosal resection (EMR), while the late recurrence rates showed no difference [12]. A subsequent randomized controlled trial (RCT) was conducted by the same team, in which non-inferiority of EMR still could not be demonstrated [13]. EMR's other drawback was that lesions larger than $2 \mathrm{~cm}$ could only be resected piecemeal and more than one-half tended to recur [14]. De Graaf et al. compared transanal excision (TAE) with TEM in 259 patients; the results showed that TEM had all-wave superiority over TAE, due to its shorter operation time and less morbidity, whereas the adenoma-free margin rate and en bloc rate were higher; the recurrence was $28.7 \%$ after TAE but $6.1 \%$ after TEM $(p<0.001)$ [15]. Results of a systematic review and meta-analysis indicated that the complete resection rate in the endoscopic submucosal dissection (ESD) patients was $74.6 \%$ and $88.5 \%$ in the TEM group; the postoperative complication rate showed no significant difference $(8.0 \%$ vs. $8.4 \%$, respectively; $p=0.874)$; the overall need of further abdominal procedures for either complications or pathological results was $8.4 \%$ in the ESD group yet $1.8 \%$ in TEM patients $(p<0.001)$ [16].

Based on the above-mentioned studies, we can conclude that TEM shows good consistency of local recurrence in treating benign rectal adenomas. To date, TEM's general indication, for less circumferential adenomas [17], might also be expanded due to its promising oncological outcome and comparatively low recurrence rate in large circumferential adenomas. 


\section{Selected T1 rectal cancer}

Morino et al. reviewed 107 patients who underwent TEM for T1 rectal cancer after a mean 54-month follow-up; patients with superficial submucosal (sm1) and middle to deep (sm2-3) tumor infiltration showed significant differences in local recurrence (0\% vs. $22.7 \%$, respectively; $p<0.05$ ), a multivariate analysis was then conducted and its results showed that alongside tumor grading, submucosal infiltration was an independent risk factor for tumor local recurrence [18].

Further studies suggested that the tumor size and staging were key factors that should be considered when defining the indication for TEM in treating rectal cancer. Doornebosch et al. reported that tumors with diameters larger than $3 \mathrm{~cm}$ would present a higher 3-year regional recurrence rate than their smaller counterparts (39\% vs. $16 \%$, respectively; $p<0.03)$, while tumors between 2 and $3 \mathrm{~cm}$ showed no significant difference from smaller ones (33 vs. $15 \%$, respectively; $p=0.1$ ) [19]. Studies showed that the local recurrence rate of TEM in treating $T 1$ rectal cancer varied from $4.1 \%$ to $24 \%$ [20-23]. Borschitz et al. explored the connection between histopathological outcomes and disease prognosis then suggested that rectal cancer with distinct pathological differentiation varied significantly in terms of the local recurrence rate [24]. Given the fact that TEM in treating early-stage rectal cancer was associated with a fluctuating local recurrence rate, its indication in primary rectal cancer was restricted to pT1NOMO, well or moderately differentiated rectal cancer [25].

On the other hand, although radical surgery could have better lymph node yields, it showed no superiority over TEM in handling highly selected T1 rectal cancer, and the long-term postoperative life quality following TEM in those patients was better, some researchers suggested that this was partly because radical operations would be more destructive, and the perioperative mortality and morbidity were higher, too [26, 27]. Yet as stated, currently TEM is applied on carefully selected T1 stage patients with "low-risk" carcinomas, and thus the conclusion that TEM had a similar local recurrence rate compared with total mesorectal excision could be drawn [28]. Another systematic review involving three RCTs also reached a similar conclusion; regardless of the fact that TEM presented a slightly higher local recurrence rate, significance could not be reached [29]. Howev- er, no superiority of TEM in T2 or higher stage cancer could be confirmed $[6,30]$.

By adding up all supportive articles and data, TEM seems to be an optimal tactic for early rectal cancer with the following features: tumor extends less than $40-50 \%$ of the rectal circumference [31, 32], a diameter less than $3 \mathrm{~cm}$ [19], confined within the upper one-third of the submucosal layer, moderate to well-differentiated tumor, cT1NO without neurovascular metastasis.

\section{Novel applications}

\section{TEM after neoadjuvant chemoradiotherapy}

Neoadjuvant chemoradiotherapy (nCRT) has succeeded in lowering the local recurrence rate. Besides a clean margin and lymph node resection, massive studies have shown that the pathological complete response $(p C R)$ might be a good indicative factor in predicting tumor recurrence as the tumor residue was nil in the resected organ [33-38]. As mentioned above, TEM alone in treating high-risk T1 stage or advanced rectal carcinomas could not demonstrate a satisfactory effect $[6,22,30]$. Whether the combination of nCRT with TEM could produce a better result calls for more studies.

Existing data in retrospective studies and prospective RCTs all indicate that clinical T2-3 rectal cancer after nCRT undergoing TEM might be feasible [39-41]. A prospective RCT in selected clinical T2 rectal cancer patients found that the local recurrence rates, distant metastases, and disease-free survival showed no statistically significant difference after 5-year minimum follow-up in post-nCRT patients receiving TEM or total mesorectal excision (TME) [41]. Marks et al. also reported that $82 \%$ of anal wounds caused by TEM following nCRT were minor, and 91\% could recover without any intervention [42]. The combination of nCRT and TEM not only showed a satisfactory local recurrence rate, but it also took advantage of TEM's minimal invasive feature in protecting patients' anal function, causing lower disturbance of patients' life quality and physical reserves [43-46].

On the other hand, the idea of watch-and-wait has drawn the attention of researchers; that is, in selected patients with an estimated clinical complete response (cCR) after $\mathrm{nCRT}$, close follow-ups could be an alternative to radical operations [47]. However, this strategy needs more investigation as there 
was no consensus on evaluating CCR [48], and some procedures in the watch-and-wait strategy, such as conducting magnetic resonance imaging scanning once a month, were less practical in remote areas. Another limitation of this strategy is that it has been reported that $3.2 \%$ to $17 \%$ of ypT0 tumors were lymph node-positive [49, 50]. On the other hand, the technique of TEM could work both diagnostically and therapeutically in suspected CCR patients, for it could resect not only the potential residual tumor but also part of the mesorectum and regional lymph nodes.

Note that in patients with a nearly complete response, a higher incomplete resection rate would be achieved once the tumor recurred [51]; therefore we assumed in tumors with an unfavorable pathologic feature, radical surgery should be performed as soon as possible.

\section{Neuroendocrine tumor}

Neuroendocrine tumors (NETs) account for about $1 \%$ of all gastrointestinal cancers; possibly owing to the prevalence of bowel cancer screening techniques such as colonoscopy, the incidence of rectal neuroendocrine tumor has increased approximately 10 -fold in the past 30 years. The rectum was the most vulnerable organ for gastrointestinal tract NETs [52-54]. Notwithstanding the low metastasis rate $(<20 \%)$ and small size, it was recommended for local resection once detected [55].

Kumar et al. conducted a retrospective analysis covering 24 patients who underwent TEM for the primary or supplementary treatment of rectal NETs; all cases were marginal negative and no recurrence was reported during a 12-year follow-up [56]. Our personal experience based on 59 patients with rectal NETs who underwent full-thickness TEM excision (38 cases for primary surgery, 21 cases for supplementary) showed no recurrence during a mean 3-year follow-up [57]; this was by far the largest published series on NET treated with TEM.

If we are to investigate the complete resection rate and possibility for salvage surgery between major endoscopic techniques such as EMR, ESD, endoscopic full-thickness resection (eFTR), and their variants, available data indicate that EMR had the least satisfactory results in en bloc resection. Moreover, although there was no significant superiority of TEM over some other techniques such as ESD in complete resection at the first attempt in small tumors $(<1 \mathrm{~cm})$,
TEM showed better efficacy in salvage surgery over other procedures and in treating NETs larger than $1 \mathrm{~cm}$; therefore patients' overall results within a single hospitalization turned out to be better one way or another [58-61].

Risk factors for NET recurrence included atypical appearance, greater size, and lymphatic invasion. Recent research indicated that for a tumor with typical appearance and size smaller than $2 \mathrm{~cm}$ in diameter, even if there was incomplete snare excision during colonoscopy, TEM or re-TEM would be safe and feasible, while in those with higher risk factors, further research was needed $[55,56]$.

\section{Gastrointestinal stromal tumor}

A gastrointestinal stromal tumor (GIST) is a rare mesenchymal tumor that affects the gastrointestinal tract. A well-accepted consensus on its treatment protocol is that a lesion greater than $2 \mathrm{~cm}$ should be considered for surgery because in this scenario the tumor's malignancy would increase. On the other hand, as reports of lymph node metastases have been limited, conventional radical resection would be an over-treatment [62].

Although sporadically reported, a combination of imatinib down-sizing together with TEM operation becomes an eye-catching new attempt in treating large, localized GIST [63-65]. It seems to offer an alternative pathway for radical resection, with potential advantages of minimal trauma, faster recovery, lower complication rate, and better life quality. A retrospective study analyzed data and outcomes from 25 cases of GIST with muscle invasion that underwent TEM with preoperative imatinib downsizing; among them 8 patients were considered as high risk for large tumor size or unpreferable pathological features. After a median follow-up of 36 months, no local recurrence or distant metastasis was observed [66]. As for the long-term outcomes, Bai et al. analyzed results of 42 cases after a median follow-up of 77 months; although the overall survival was $100 \%$, local recurrence occurred in 3 patients and one of them developed distant metastasis 112 months after the surgery; this was reported to be by far the largest study on GIST treated by TEM [67]. Note that a negative margin was a key factor of less local recurrence; in those with positive margins, re-TEM or imatinib adjuvant therapy should be taken into consideration [68].

By summarizing available studies we can conclude that a novel treatment protocol might be es- 
tablished in medical centers with the experience of performing TEM, that is, when the rectal GIST was confirmed after biopsy, for small ones located within $7 \mathrm{~cm}$ of the anal verge, transanal local excision would be the first choice. Neoadjuvant imatinib therapy could be adopted in tumors with the following features: tumor diameter $>3 \mathrm{~cm}$, immunohistochemical positive for CD117, adhesion between tumor and its surrounding tissue, with or without a high mitotic index (> 5/50 high power field), after a dosage of $400 \mathrm{mg}$ of imatinib mesylate per day for 6 months; the mean maximum tumor diameter should significantly decrease and then the transanal surgery should be performed. Postoperative adjuvant therapy would be optional according to the pathological outcomes $[66,67]$.

Fistula between the rectum and its adjacent organs

Fistulae are common complications in general surgery, gynecology, and urology; they are caused by iatrogenic misoperation or congenital defects. In complex ones, multidisciplinary works for radical repair were needed. Most operations were conducted either transsphincterically or transperineally [69]. Kanehira et al. reported a 10-patient study using TEM treating rectovesical fistula (RVF); all fistulae were iatrogenically caused after prostatectomy, no intraoperative and postoperative complications were reported and a total cure rate of $70 \%$ was achieved [70]. They concluded that the other 3 failed repairs were owing to patients' large fistula orifices or complicated medical histories, such as a history of multiple operations or high intensity focused ultrasound ablation (HIFU). However, other reports offered some successful examples of TEM treating post-HIFU fistulae; the fistula's complexity, rather than how long the patient's history was or what organ the rectum connected to seemed to be a determining factor for a successful repair $[71,72]$.

Due to the rarity of this procedure, large-scale studies on RVF that underwent TEM were lacking, and most cases were sporadically reported. A retrospective study involving 13 patients revealed that after a median follow-up of 25 months, 1 patient experienced recurrence, and her RVF was repaired using TEM again [73]. In our experience in treating recurrent rectovaginal fistula, sclerotic scars and their surrounding tissues were major causes of recurrent fistula; with the help of TEM's 3-dimensional view and up to 6-fold magnification vision, those tissues could be removed precisely by needle diathermy without sacrificing too much normal tissue [74]. Consequently, a relief of tension between the sutured edges could be achieved.

\section{Solitary rectal ulcer syndrome (SRUS) and benign stricture}

Solitary rectal ulcer syndrome (SRUS) is a chronic nonspecific anorectal disease with the main symptoms of hematochezia, mucous stool, anorectal pain, and dyschezia. It is more common in adults and has no gender difference. The characteristic endoscopic features of SRUS are erythema and polypoid lesion in the distal rectum, with solitary ulcer [75]. Published retrospective studies have reported several cases that were treated as malignant tumors but confirmed as solitary rectal ulcers by pathological examinations; no local recurrence was found after close follow-ups [76-78]. On the other hand, with the help of its magnified vision and inflated endoluminal space, TEM has also been used as a supporting platform in benign stricture laser ablation since 1997 [79]. Baatrup et al. pushed this indication a step forward by adopting TEM's full-thickness resection feature, namely, the feasibility of the full-thickness resection of anal fibrosis by purely using TEM equipment was confirmed, and satisfactory long-term anatomical and functional results were observed [80].

\section{Transanal total mesorectal excision}

First reported by Sylla et al. [81] in 2010, transanal total mesorectal excision gained worldwide attention for its revolutionary "bottom to up" approach and promising outcomes. This technique was an attempt to solve some bothersome issues in the traditional TME technique, for instance, correctly locating the distal edge of the tumor, operating within a narrow pelvic space, dissecting the lower two-thirds of the peripheral rectum, and so on. Meta-analysis research involving 573 patients showed that transanal total mesorectal excision (TaTME) had no differences from traditional laparoscopic TME in lymph node dissection, distal resection margin (DRM), and positive DRM rate. Moreover, it presented a higher rate of achieving complete mesorectal excision, as well as a longer circumferential resection margin (CRM) and less involvement of positive CRM. Although perioperative outcomes, hospital stay, intraoperative complications, and readmission 
were comparable, a noteworthy lower rate of overall postoperative complications was also observed [82]. Additional studies showed that intraoperative blood loss, operation time, and readmission rate were also comparable or lower in the TaTME group $[83,84]$.

Depending on the different apparatus TaTME may employ, TaTME can be divided into TaTME via TEM, also referred to as TEM-TME, or TaTME via the TAMIS platform (transanal minimally invasive surgery approach, TAMIS-TME). No comparison between these two procedures has been made yet. Whereas the former platform requires specific equipment and rich experience in TEM technique, it takes full advantage of TEM's clear vision and constant endoluminal air insufflation. Published data showed that experimental TEM-TME was performed earlier and more frequently on swine and cadavers than its counterpart [85-87]. Rouanet et al. reported a series involving 30 patients with advanced or recurrent rectal cancers treated with TEM-TME; every patient had either unfavorable tumor characteristics or anatomical defects, a complete resection rate of $87 \%$ was obtained amongst them, 4 patients reported local recurrence after a mean 21-month follow-up, and the overall 1-year survival rate was $96.6 \%$ [88].

Up to now, TaTME is still in its infancy. Since its learning curve is comparatively long and long-term outcomes remained to be examined, large trials on live patients with either TEM-TME or TAMIS-TME have been lacking. A worldwide consensus has not been established on TaTME's application in advanced rectal cancer yet. Hence, more studies on this new technique are to be expected and more studies comparing TEM-TME versus TAMIS-TME are awaited. For surgeons who are skilled in TEM procedures, the curve might be flattened.

\section{Conclusions}

Although first introduced 38 years ago, TEM has proved itself a vibrant technique and fundamental platform in treating diseases of other disciplines. We assume that its primal indication of small benign adenomas was comparatively mature yet the application of TEM could be expanded to larger ones, its application in rectal cancer could be more flexible and early-stage cancer should not limit the popularization of TEM in large medical institutions, especially in selected patients after neoadjuvant chemoradiotherapy.
TEM's niche applications in NET, GIST, RVF, SRUS, and benign stricture were found to be promising even if prospective studies have been limited. It would provide a novel perspective for clinical studies. Its role in TaTME would be a feasible example of combining natural orifice transluminal endoscopic surgery and minimally invasive surgery. We look forward to more and more bold and creative applications of TEM in the future.

\section{Acknowledgments}

The work was supported by the Major Grants Program of Beijing Science and Technology Commission (No. D171100002617003).

\section{Conflict of interest}

The authors declare no conflict of interest.

\section{References}

1. Buess G, Theiss R, Hutterer F, et al. Transanal endoscopic surgery of the rectum - testing a new method in animal experiments. Leber Magen Darm 1983; 13: 73-7.

2. Buess G. Review: transanal endoscopic microsurgery (TEM). J Royal Coll Surg 1993; 38: 239-45.

3. Heidary B, Phang TP, Raval MJ, et al. Transanal endoscopic microsurgery: a review. Can I Surg 2014; 57: 127-38.

4. de Graaf EJ. Transanal endoscopic microsurgery. Scand I Gastroenterol Suppl 2003; 239: 34-9.

5. Guerrieri M, Baldarelli M, Organetti L, et al. Transanal endoscopic microsurgery for the treatment of selected patients with distal rectal cancer: 15 years experience. Surg Endosc 2008; 22: 2030-5.

6. Tsai BM, Finne CO, Nordenstam JF, et al. Transanal endoscopic microsurgery resection of rectal tumors: outcomes and recommendations. Dis Colon Rectum 2010; 53: 16-23.

7. Platell C. Transanal endoscopic microsurgery. ANZ I Surg 2009; 79: 275-80.

8. Allaix ME, Arezzo A, Cassoni P, et al. Recurrence after transanal endoscopic microsurgery for large rectal adenomas. Surg Endosc 2012; 26: 2594-600.

9. Whitehouse PA, Armitage JN, Tilney HS, et al. Transanal endoscopic microsurgery: local recurrence rate following resection of rectal cancer. Colorectal Dis 2008; 10: 187-93.

10. Whitehouse PA, Tilney HS, Armitage JN, et al. Transanal endoscopic microsurgery: risk factors for local recurrence of benign rectal adenomas. Colorectal Dis 2006; 8: 795-9.

11. Arezzo A, Arolfo S, Allaix ME, et al. Transanal endoscopic microsurgery for giant circumferential rectal adenomas. Colorectal Dis 2016; 18: 897-902.

12. Barendse RM, van den Broek FJ, van Schooten J, et al. Endoscopic mucosal resection vs transanal endoscopic microsurgery for the treatment of large rectal adenomas. Colorectal Dis 2012; 14: e191-6. 
13. Barendse RM, Musters GD, de Graaf EJR, et al. Randomised controlled trial of transanal endoscopic microsurgery versus endoscopic mucosal resection for large rectal adenomas (TREND Study). Gut 2018; 67: 837-46.

14. Puli SR, Kakugawa Y, Gotoda T, et al. Meta-analysis and systematic review of colorectal endoscopic mucosal resection. World J Gastroenterol 2009; 15: 4273-7.

15. de Graaf EJ, Burger JW, van ljsseldijk AL, et al. Transanal endoscopic microsurgery is superior to transanal excision of rectal adenomas. Colorectal Dis 2011; 13: 762-7.

16. Arezzo A, Passera R, Saito Y, et al. Systematic review and meta-analysis of endoscopic submucosal dissection versus transanal endoscopic microsurgery for large noninvasive rectal lesions. Surg Endosc 2014; 28: 427-38.

17. Demartines N, von Flue MO, Harder FH. Transanal endoscopic microsurgical excision of rectal tumors: indications and results. World J Surg 2001; 25: 870-5.

18. Morino M, Allaix ME, Caldart M, et al. Risk factors for recurrence after transanal endoscopic microsurgery for rectal malignant neoplasm. Surg Endosc 2011; 25: 3683.

19. Doornebosch PG, Zeestraten E, de Graaf EJ, et al. Transanal endoscopic microsurgery for T1 rectal cancer: size matters! Surg Endosc 2012; 26: 551-7.

20. Lee W, Lee D, Choi S, et al. Transanal endoscopic microsurgery and radical surgery for $\mathrm{T} 1$ and $\mathrm{T} 2$ rectal cancer. Surg Endosc 2003; 17: 1283-7.

21. Winde G, Nottberg H, Keller R, et al. Surgical cure for early rectal carcinomas (T1). Transanal endoscopic microsurgery vs. anterior resection. Dis Colon Rectum 1996; 39: 969-76.

22. De Graaf EJ, Doornebosch PG, Tollenaar RA, et al. Transanal endoscopic microsurgery versus total mesorectal excision of T1 rectal adenocarcinomas with curative intention. Eur J Surg Oncol 2009; 35: 1280-5.

23. Junginger T, Goenner U, Hitzler M, et al. Analysis of local recurrences after transanal endoscopic microsurgery for low risk rectal carcinoma. Int J Colorectal Dis 2017; 32: 265-71.

24. Borschitz T, Heintz A, Junginger T. The influence of histopathologic criteria on the long-term prognosis of locally excised $\mathrm{pT} 1$ rectal carcinomas: results of local excision (transanal endoscopic microsurgery) and immediate reoperation. Dis Colon Rectum 2006; 49: 1492-506.

25. Lu JY, Lin GL, Qiu HZ, et al. Comparison of transanal endoscopic microsurgery and total mesorectal excision in the treatment of T1 rectal cancer: a meta-analysis. PLoS One 2015; 10: e0141427.

26. Hompes R, Ashraf SQ, Gosselink MP, et al. Evaluation of quality of life and function at 1 year after transanal endoscopic microsurgery. Colorectal Dis 2015; 17: 054-61.

27. Zieren J, Paul M, Menenakos C. Transanal endoscopic microsurgery (TEM) vs. radical surgery (RS) in the treatment of rectal cancer: indications, limitations, prospectives. A review. Acta Gastroenterol Belg 2007; 70: 374-80.

28. Heintz A, Morschel M, Junginger T. Comparison of results after transanal endoscopic microsurgery and radical resection for $\mathrm{T} 1$ carcinoma of the rectum. Surg Endosc 1998; 12: 1145-8.

29. Veereman G, Vlayen J, Robays J, et al. Systematic review and meta-analysis of local resection or transanal endoscopic micro- surgery versus radical resection in stage i rectal cancer: a real standard? Crit Rev Oncol Hematol 2017; 114: 43-52.

30. Bacic D, Durut I, Bukvic N, et al. Transanal endoscopic microsurgery (TEM): alternative or a method of choice in treating tumors of the rectum with appropriately selected patients? Coll Antropol 2014; 38: 1127-30.

31. Robek O, Can V, Svoboda T, et al. Transanal endoscopic microsurgery (TEM) our experience. Rozhl Chir 2016; 95: 33-9.

32. Lin GL, Qiu HZ, Xiao Y, et al. Transanal endoscopic microsurgery for rectal intraepithelial neoplasia and early rectal carcinoma. Zhonghua Wei Chang Wai Ke Za Zhi 2008; 11: 39-43.

33. Kalady MF, de Campos-Lobato LF, Stocchi L, et al. Predictive factors of pathologic complete response after neoadjuvant chemoradiation for rectal cancer. Ann Surg 2009; 250: 582-89.

34. Habr-Gama A, Perez RO, Proscurshim I, et al. Interval between surgery and neoadjuvant chemoradiation therapy for distal rectal cancer: does delayed surgery have an impact on outcome? Int J Radiat Oncol Biol Phys 2008; 71: 1181-8.

35. de Campos-Lobato LF, Geisler DP, Moreira AD, et al. Neoadjuvant therapy for rectal cancer: the impact of longer interval between chemoradiation and surgery. J Gastrointest Surg 2011; 15: 444-50.

36. Tulchinsky H, Shmueli E, Figer A, et al. An interval > 7 weeks between neoadjuvant therapy and surgery improves pathologic complete response and disease-free survival in patients with locally advanced rectal cancer. Ann Surg Oncol 2008; 15: 2661-67.

37. Sloothaak DAM, Geijsen DE, van Leersum NJ, et al. Optimal time interval between neoadjuvant chemoradiotherapy and surgery for rectal cancer. Br J Surg 2013; 100: 933-U108.

38. Biondo S, Fraccalvieri D, Golda T, et al. Update on advances and controversy in rectal cancer treatment. Tech Coloproctology 2016; 20: 145-52.

39. Borschitz T, Wachtlin D, Mohler M, et al. Neoadjuvant chemoradiation and local excision for T2-3 rectal cancer. Ann Surg Oncol 2008; 15: 712-20.

40. Lezoche E, Baldarelli M, Lezoche G, et al. Randomized clinical trial of endoluminal locoregional resection versus laparoscopic total mesorectal excision for 72 rectal cancer after neoadjuvant therapy. Br J Surg 2012; 99: 1211-8.

41. Lezoche G, Baldarelli M, Guerrieri M, et al. A prospective randomized study with a 5-year minimum follow-up evaluation of transanal endoscopic microsurgery versus laparoscopic total mesorectal excision after neoadjuvant therapy. Surg Endosc 2008; 22: 352-8.

42. Marks JH, Valsdottir EB, DeNittis A, et al. Transanal endoscopic microsurgery for the treatment of rectal cancer: comparison of wound complication rates with and without neoadjuvant radiation therapy. Surg Endosc 2009; 23: 1081-7.

43. D’Ambrosio G, Paganini AM, Balla A, et al. Quality of life in non-early rectal cancer treated by neoadjuvant radio-chemotherapy and endoluminal loco-regional resection (ELRR) by transanal endoscopic microsurgery (TEM) versus laparoscopic total mesorectal excision. Surg Endosc 2016; 30: 504-11.

44. Coco C, Rizzo G, Mattana C, et al. Transanal endoscopic microsurgery after neoadjuvant radiochemotherapy for locally advanced extraperitoneal rectal cancer: short-term morbidity and functional outcome. Surg Endosc 2013; 27: 2860-7. 
45. Biviano I, Balla A, Badiali D, et al. Anal function after endoluminal locoregional resection by transanal endoscopic microsurgery and radiotherapy for rectal cancer. Colorectal Dis 2017; 19: 0177-85.

46. Issa N, Murninkas A, Schmilovitz-Weiss H, et al. Transanal endoscopic microsurgery after neoadjuvant chemoradiotherapy for rectal cancer. J Laparoendosc Adv Surg Tech A 2015; 25: 617-24.

47. Habr-Gama A, Sabbaga J, Gama-Rodrigues J, et al. Watch and wait approach following extended neoadjuvant chemoradiation for distal rectal cancer: are we getting closer to anal cancer management? Dis Colon Rectum 2013; 56: 1109-17.

48. Maas M, Lambregts DM, Nelemans PJ, et al. Assessment of clinical complete response after chemoradiation for rectal cancer with digital rectal examination, endoscopy, and MRI: selection for organ-saving treatment. Ann Surg Oncol 2015; 22: 3873-80.

49. Mignanelli ED, de Campos-Lobato LF, Stocchi L, et al. Downstag ing after chemoradiotherapy for locally advanced rectal cancer: is there more (tumor) than meets the eye? Dis Colon Rectum 2010; 53: 251-6.

50. Hughes R, Glynne-Jones R, Grainger J, et al. Can pathological complete response in the primary tumour following pre-operative pelvic chemoradiotherapy for T3-T4 rectal cancer predict for sterilisation of pelvic lymph nodes, a low risk of local recurrence and the appropriateness of local excision? Int J Colorectal Dis 2006; 21: 11-7.

51. Perez RO, Habr-Gama A, Sao Juliao GP, et al. Transanal endoscopic microsurgery (TEM) following neoadjuvant chemoradiation for rectal cancer: outcomes of salvage resection for local recurrence. Ann Surg Oncol 2016; 23: 1143-48.

52. Chablaney S, Zator ZA, Kumta NA. Diagnosis and management of rectal neuroendocrine tumors. Clin Endosc 2017; 50: 530-36.

53. Oberg K. Medical therapy of gastrointestinal neuroendocrine tumors. Visceral Med 2017; 33: 352-6.

54. Practice guideline neuroendocrine tumors - AWMF-Reg. 021 27. Z Gastroenterol 2018; 56: 583-681.

55. Basuroy R, Haji A, Ramage JK, et al. Review article: the investigation and management of rectal neuroendocrine tumours. Aliment Pharmacol Ther 2016; 44: 332-45.

56. Kumar AS, Sidani SM, Kolli K, et al. Transanal endoscopic microsurgery for rectal carcinoids: the largest reported United States experience. Colorect Dis 2012; 14: 562-6.

57. Chen WJ, Wu N, Zhou JL, et al. Full-thickness excision using transanal endoscopic microsurgery for treatment of rectal neuroendocrine tumors. World J Gastroenterol 2015; 21: 9142-9.

58. Choi HH, Kim JS, Cheung DY, et al. Which endoscopic treatment is the best for small rectal carcinoid tumors? World J Gastrointest Endosc 2013; 5: 487-94.

59. Kwaan MR, Goldberg JE, Bleday R. Rectal carcinoid tumors: review of results after endoscopic and surgical therapy. Arch Surg 2008; 143: 471-5.

60. Brand M, Reimer S, Reibetanz J, et al. Endoscopic full thickness resection vs. transanal endoscopic microsurgery for local treatment of rectal neuroendocrine tumors - a retrospective analysis. Int J Colorectal Dis 2021; 36: 971-6.

61. Jeon JH, Cheung DY, Lee SJ, et al. Endoscopic resection yields reliable outcomes for small rectal neuroendocrine tumors. Dig Endosc 2014; 26: 556-63.
62. Duek SD, Kluger Y, Grunner S, et al. Transanal endoscopic microsurgery for the resection of submucosal and retrorectal tumors. Surg Laparosc Endosc Percutan Tech 2013; 23: 66-8.

63. Liu Q, Zhong G, Zhou W, et al. Initial application of transanal endoscopic microsurgery for high-risk lower rectal gastrointestinal stromal tumor after imatinib mesylate neoadjuvant chemotherapy: a case report. Medicine 2017; 96: e7538.

64. Arezzo A, Verra M, Morino M. Transanal endoscopic microsurgery after neoadjuvant therapy for rectal GIST. Dig Liver Dis 2011; 43: 923-4.

65. Tielen R, Bremers AJ, van der Graaf WT, et al. Transanal endoscopic microsurgery following treatment with imatinib: a case report of a patient with a rectal gastrointestinal stromal tumor. Acta Chir Belg 2015; 115: 166-9.

66. Han X, Xu J, Qiu H, et al. A novel curative treatment strategy for patients with lower grade rectal gastrointestinal stromal tumor: chemoreduction combined with transanal endoscopic microsurgery. J Laparoendosc Adv Surg Tech A 2017; 27: 579-85.

67. Bai X, Zhou W, Li Y, et al. Transanal endoscopic microsurgery with alternative neoadjuvant imatinib for localized rectal gastrointestinal stromal tumor: a single center experience with long-term surveillance. Surg Endosc 2021; 35: 3607-17.

68. Punnen S, Karimuddin AA, Raval MJ, et al. Transanal endoscopic microsurgery (TEM) for rectal GI stromal tumor. Am J Surg 2021; 221: 183-6.

69. Crestani A, Dal Moro F. Surgical treatment of rectourinary fistulas: review of the literature. Urologia 2015; 82: 30-5.

70. Kanehira E, Tanida T, Kamei A, et al. Transanal endoscopic microsurgery for surgical repair of rectovesical fistula following radical prostatectomy. Surg Endosc 2015; 29: 851-5.

71. Bochove-Overgaauw DM, Beerlage HP, Bosscha K, et al. Transanal endoscopic microsurgery for correction of rectourethral fistulae. J Endourol 2006; 20: 1087-90.

72. Andrews EJ, Royce P, Farmer KC. Transanal endoscopic microsurgery repair of rectourethral fistula after high-intensity focused ultrasound ablation of prostate cancer. Colorect Dis 2011; 13: 342-3.

73. D’Ambrosio G, Paganini AM, Guerrieri M, et al. Minimally invasive treatment of rectovaginal fistula. Surg Endosc 2012; 26 : 546-50.

74. Chen W, Chen X, Lin G, et al. Successful repair of recurrent rectovaginal fistula by stratified suture using transanal endoscopic microsurgery: a CARE-compliant case report. Medicine 2016; 95: e4600.

75. Zhu QC, Shen RR, Qin HL, et al. Solitary rectal ulcer syndrome: clinical features, pathophysiology, diagnosis and treatment strategies. World J Gastroenterol 2014; 20: 738-44.

76. Lloyd GM, Sutton CD, Marshall LJ, et al. Transanal endoscopic microsurgery: lessons from a single UK centre series. Colorectal Dis 2002; 4: 467-72.

77. Palma P, Freudenberg S, Samel S, et al. Transanal endoscopic microsurgery: indications and results after 100 cases. Colorectal Dis 2004; 6: 350-5.

78. Røkke O, Iversen KB, Ovrebø K, et al. Local resection of rectal tumors by transanal endoscopic microsurgery: experience with the first 70 cases. Dig Surg 2005; 22: 182-9. 
79. Kato K, Saito T, Matsuda M, et al. Successful treatment of a rectal anastomotic stenosis by transanal endoscopic microsurgery (TEM) using the contact Nd:YAG laser. Surg Endosc 1997; 11: 485-7.

80. Baatrup G, Svensen R, Ellensen VS. Benign rectal strictures managed with transanal resection: a novel application for transanal endoscopic microsurgery. Colorectal Dis 2010; 12: 144-6.

81. Sylla P, Rattner DW, Delgado S, et al. NOTES transanal rectal cancer resection using transanal endoscopic microsurgery and laparoscopic assistance. Surg Endosc 2010; 24: 1205-10.

82. Ma B, Gao P, Song Y, et al. Transanal total mesorectal excision (taTME) for rectal cancer: a systematic review and meta-analysis of oncological and perioperative outcomes compared with laparoscopic total mesorectal excision. BMC Cancer 2016; 16: 380.

83. Simillis C, Hompes R, Penna M, et al. A systematic review of transanal total mesorectal excision: is this the future of rectal cancer surgery? Colorectal Dis 2016; 18: 19-36.

84. Fernandez-Hevia M, Delgado S, Castells A, et al. Transanal total mesorectal excision in rectal cancer: short-term outcomes in comparison with laparoscopic surgery. Ann Surg 2015; 261: 221-7.

85. Whiteford MH, Denk PM, Swanstrom LL. Feasibility of radical sigmoid colectomy performed as natural orifice translumenal endoscopic surgery (NOTES) using transanal endoscopic microsurgery. Surg Endosc 2007; 21: 1870-4.

86. Telem DA, Han KS, Kim MC, et al. Transanal rectosigmoid resection via natural orifice translumenal endoscopic surgery (NOTES) with total mesorectal excision in a large human cadaver series. Surg Endosc 2013; 27: 74-80.

87. McLemore EC, Coker AM, Devaraj B, et al. TAMIS-assisted laparoscopic low anterior resection with total mesorectal excision in a cadaveric series. Surg Endosc 2013; 27: 3478-84.

88. Rouanet P, Mourregot A, Azar CC, et al. Transanal endoscopic proctectomy: an innovative procedure for difficult resection of rectal tumors in men with narrow pelvis. Dis Colon Rectum 2013; 56: 408-15.

Received: 4.06.2021, accepted: 24.07.2021 